\title{
Is $\mathrm{KCNH} 1$ mutation related to coronary artery ectasia
}

\author{
Mohammad Rafi Noori, Bo Zhang (iD and Lifei Pan
}

\begin{abstract}
Background: Coronary artery ectasia (CAE) is an uncommon finding in patients undergoing coronary angiography and acute myocardial infarction is an extremely uncommon condition in the presence of coronary artery ectasia. To date, 50 gene variants associated with coronary artery disease have been identified, but none appear to be related to coronary artery ectasia.

Case presentation: This is a rare case of Coronary artery ectasia which is considered to be related to Gene variations in potassium voltage-gated channel subfamily $\mathrm{H}$ member 1, KCNH1 (encoding a protein designated ether à go-go, EAG1 or KV10.1).

Conclusion: Occurrence of Acute myocardial infarction in patient with coronary artery ectasia after diarrhea is a very rare condition and involvement of $\mathrm{KCNH} 1$ gene mutation which is described in this case report.
\end{abstract}

Keywords: Coronary artery ectasia, Acute myocardial infarction, $\mathrm{KCNH1}$, Gene mutation, Diarrhea, Embolism

\section{Background}

Coronary artery ectasia (CAE) is defined as dilation of the coronary vascular lumen up to a diameter 1.5 times that of the adjacent normal coronary artery $[1,2]$. Angina pectoris is the most common clinical manifestation [3] while acute myocardial infarction is an extremely uncommon condition in the presence of coronary artery ectasia, detected only in $<1 \%$ cases [4]. Genetic variation has been reported as one of the risk factors for coronary artery disease. To date, 50 gene variants associated with coronary artery disease have been identified [5], but none appear to be related to coronary artery ectasia.

Here, we have reported a rare case of acute myocardial infarction with coronary artery ectasia and mutation in potassium voltage-gated channel subfamily $H$ member 1 , KCNH1 (encoding a protein designated ether à go-go, EAG1 or KV10.1) gene.

\footnotetext{
* Correspondence: dalianzhangbo@yahoo.com

All authors confirmed that this manuscript has not been previously published and is not currently under consideration by any other journal. Additionally, all of the authors have approved the contents of this paper and have agreed to the policies.

Department of Coronary Heart Disease, The first affiliated Hospital of Dalian Medical University, Lianhe Avenue, Dalian, China
}

\section{Case presentation}

A 33-years-old male was admitted into our hospital after $3 \mathrm{hrs}$ of intermittent chest pain. Previously, the patient was admitted to our hospital and diagnosed with firstdegree atrioventricular conduct block and coronary artery ectasia, which was conservatively treated with aspirin $(100 \mathrm{mg} / \mathrm{qd}$, atorvastatin $20 \mathrm{mg} / \mathrm{qd})$ on a routine basis. After 7-8 episodes of diarrhea, the patient experiences a similar chest pain to previous episodes. Electrocardiography (ECG) was performed immediately, which disclosed ST elevation in inferior leads (II, III and avF). The patient was defibrillated after developing a sudden ventricular fibrillation.

On admission, his pulse was recorded as $72 / \mathrm{min}$ and blood pressure (BP) as $120 / 70 \mathrm{mmHg}$. In laboratory examinations, cardiac enzyme contents were as follows: creatine kinase (CK) $413 \mathrm{IU} / \mathrm{L}$, high-sensitivity troponin I (hs-TnI) $3.303 \mu \mathrm{g} / \mathrm{L}$, creatine kinase muscle/brain mass (CK-MBmass) $36.94 \mu \mathrm{g} / \mathrm{L}$. The consequent diagnosis was acute ST elevation myocardial infarction (STEMI). The patient underwent elective coronary angiography, which revealed normal left main coronary artery (LMCA), left anterior descending (LAD) middle segment light stenosis with aneurysm-like ectasia and aneurysm-like ectasia of proximal left circumflex artery (LCX), as well as aneurysm-like ectasia of middle segment and thrombus

(c) The Author(s). 2019 Open Access This article is distributed under the terms of the Creative Commons Attribution 4.0 International License (http://creativecommons.org/licenses/by/4.0/), which permits unrestricted use, distribution, and 
in the distal segment of right coronary artery (RCA) (Fig. 1a-c).

Despite angiographic detection of a thrombus, conservative therapy (aspirin $100 \mathrm{mg} / \mathrm{qd}$, ticagrelor $90 \mathrm{mg} / \mathrm{tid}$, atorvastatin $20 \mathrm{mg} / \mathrm{qd}$ ) appeared the optimal treatment choice. For further examination of cardiac function, echocardiography was performed, which revealed right and left ventricle regional wall motion abnormalities, left ventricle diameter of $55 \mathrm{~mm}$, and left ventricle ejection fraction (LVEF) of $56 \%$.

During history taking, the patient provided information on the medical history of his father who was admitted to another hospital due to a similar complaint of chest discomfort and underwent coronary angiography, which showed ectasia of the middle to distal segment of RCA and mid segment of LAD and normal LMCA, LCX (Fig. 1d-f). For analysis of the genetic relationships, high throughput sequencing testing was conducted, as depicted in (Fig. 2).

After 1 year of conservative therapy, the patient was re-admitted to our hospital due to short episodes of chest pain, which usually ended within a few seconds. Computed tomography angiography (CTA) revealed normal LMT, slight calcification and ectasia of LAD, LCX, and RCA (Fig. 3). Rivaroxaban $10 \mathrm{mg}$ Qd was selected for anticoagulant therapy, along with atorvastatin $20 \mathrm{mg} / \mathrm{qd}$.

\section{Discussion}

CAE is only observed in 5\% patients undergoing coronary angiography. Overall, 20-30\% CAE cases are congenital, with the remainder being acquired, and up to $20 \%$ acquired CAE is attributed to atherosclerosis, which is mostly associated with obstructive coronary artery disease [6]. Congenital CAE is mainly linked to cardiac anomalies, such as bicuspid aortic valve, aortic root dilation, ventricular septal defect or pulmonary stenosis [6, 7]. Acquired CAE association with inflammatory or connective tissue disorder constitutes only $10-20 \%$ cases, such as scleroderma Elhers-Danlos syndrome, anti-neutrophil cytoplasmic antibody-related vasculitis syphilitic aortitis and Kawasaki disease [8]. All the above etiologies of coronary artery ectasia were excluded based on patient history and serological test findings.

Disturbances in blood flow filling and washout are an inherent characteristic of CAE [9]. which may be the basis of ischemia or ischemic events in this patient group, and can alter the incidence of exercise-induced angina pectoris or myocardial infarction regardless of the severity of coexisting stenotic lesions. Slow blood flow to ectatic segments of coronary artery is reported to induce activation of platelets, coagulation and thrombus formation [10].

Before admission to the hospital, the patient experienced several episodes of diarrhea, which could cause
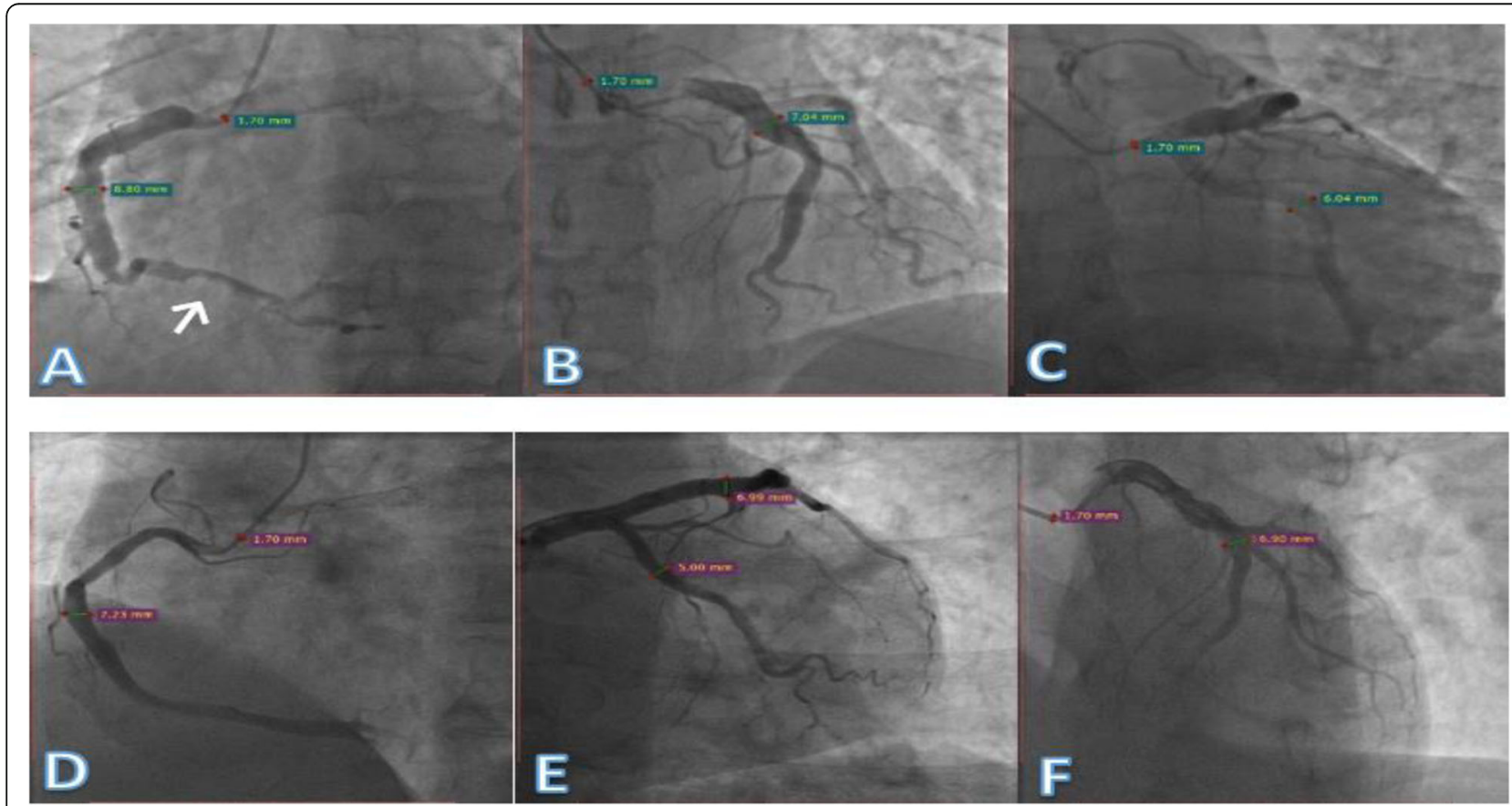

Fig. 1 a: Left anterior oblique view of ectatic right coronary artery with diameter of $8.80 \mathrm{~mm}$ and thrombus in the distal portion of RCA (arrow). b, c: Ectasia of left anterior descending artery and left circumflex artery with diameter of 7.04 and 6.04 (respectively), in the right cranial and caudal views. d: Ectasia in mid to distal segment of RCA with diameter of $7.23 \mathrm{~mm}$. E, F: Ectasia in proximal to mid segment of LAD with diameter of $6.99 \mathrm{~mm}$ 


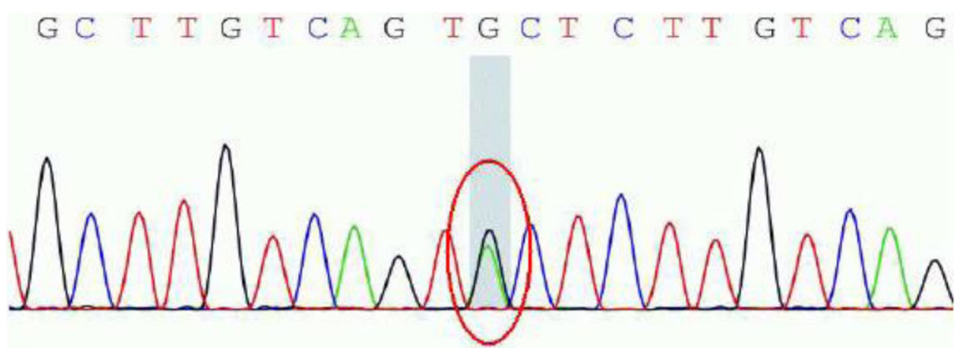

\section{c. $470 \mathrm{C}>\mathrm{T}$ heterozygous mutation in chr1:211256210 of patient}

G C T I G I C A G I G C I C T T G T C A G

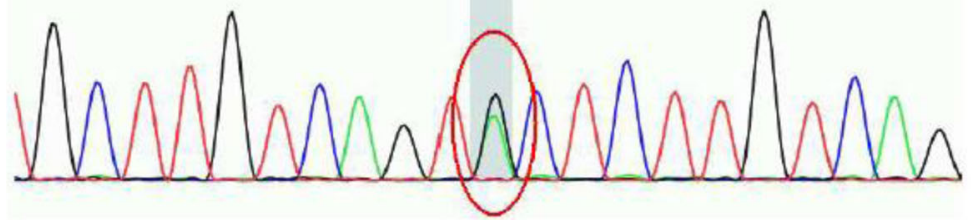

c. $470 \mathrm{C}>$ T heterozygous mutation in chr1:211256210 of patient's father.

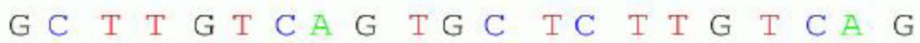

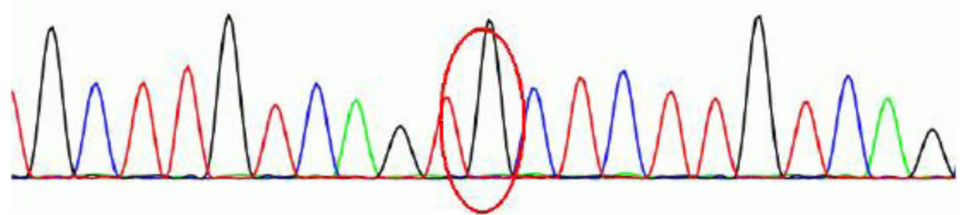

No mutation found in chr1:211256210 of patient's mother.

Fig. 2 Pyrosequencing profiles of three genotypes of the C.470C > T (chr1:211256210) KCNH1 mutation were identified. The patient and his father carried the same genetic mutation but not his mother. Genetic mutational analysis was performed using www.precisionmdx.com

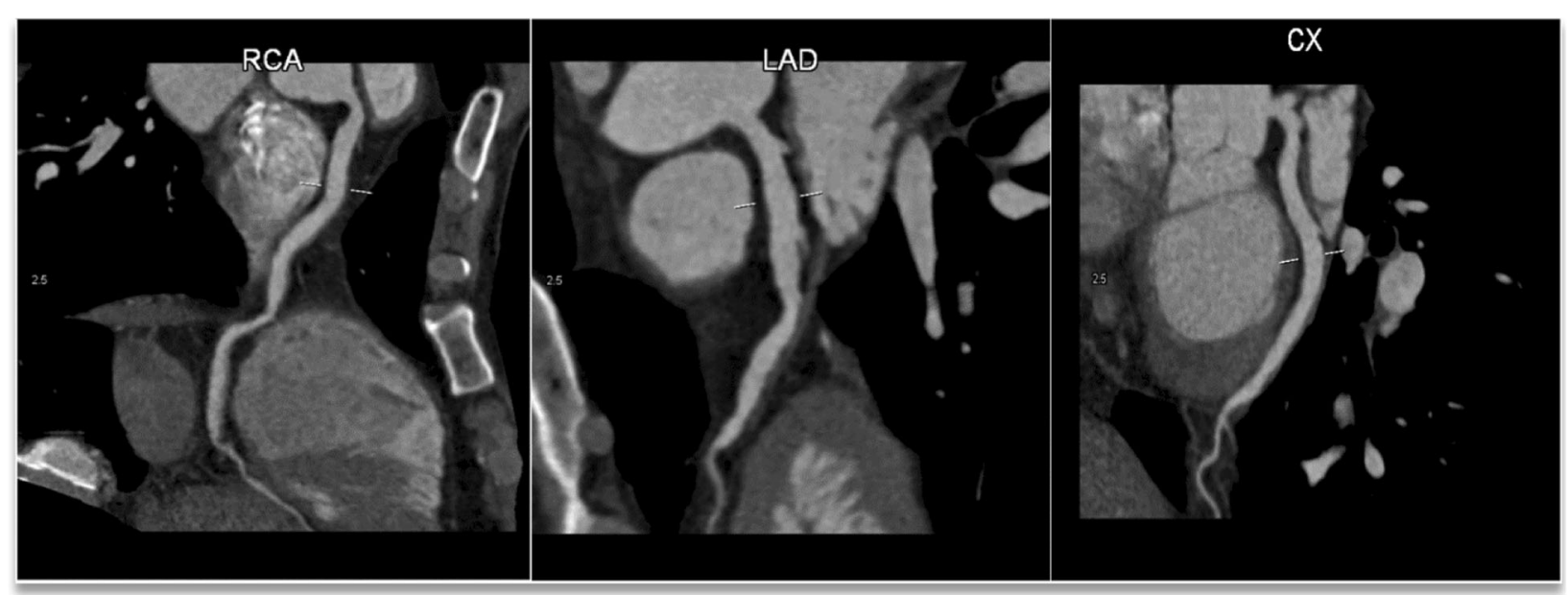

Fig. 3 Right coronary artery with a diameter of $8.80 \mathrm{~mm}$, left anterior descending artery with a diameter of $7.04 \mathrm{~mm}$, left circumflex artery with a diameter of $6.04 \mathrm{~mm}$ 
dehydration (loss of body fluid), leading to higher concentrations of chemicals circulating in blood and increased serum osmolality, culminating in ectatic artery and consequent disturbance in blood flow, in turn, triggering formation of thrombus in the right coronary artery. After a year of follow-up, coronary CT angiography confirmed absence of thrombus in RCA. Accordingly, anticoagulant therapy with rivaroxaban $10 \mathrm{mg}$ alone was selected for treatment.

KCNH1 (encoding ether à go-go, EAG1 or KV10.1), a voltage-gated potassium channel, is predominantly expressed in the central nervous system (CNS) [11].and its overexpression provides growth advantages to cancer cells and enhances proliferation. Mutations in the KCNH1 gene are reported to be associated with Zimmerman-Laband syndrome and Temple-Baraitser syndrome, characterized by intellectual disability, epilepsy, hypoplasia abnormal muscle tone and craniofacial dysmorphology [12]. Epilepsy is the main manifestation of $\mathrm{KCNH} 1$ mutation-induced disorders. However, our patient had none of the above features or epileptic history.

To our knowledge, this is the first documented report linking $\mathrm{KCNH} 1$ mutation to coronary heart disease. The detection of mutations in both family members suggests that $K C N H 1$ abnormalities are significantly involved in this condition. Further studies focusing on the KCNH1 gene and the mechanisms underlying its specific association with coronary artery disease are thus warranted.

\begin{abstract}
Abbreviation
BP: Blood pressure; CAE: Coronary artery ectasia; CK: Creatine kinase; CKMBmass: Creatine kinase muscle/brain mass; CNS: Central nervous system; CTA: Computed tomography angiography; ECG: Electrocardiography; hsTnl: High-sensitivity troponin I; KCNH1: Potassium voltage-gated channel subfamily $\mathrm{H}$ member 1; LAD: Left anterior descending; LCX: Left circumflex artery; LMCA: Left Main coronary artery; LVEF: Left ventricle ejection fraction; RCA: Right coronary artery; STEMI: ST elevation myocardial infarction
\end{abstract}

\section{Acknowledgements}

We would like to express our gratitude to Tong Tao, Cath-lab technician in the Department of.

Coronary Heart disease for the high-quality images in this case.

\section{Authors' contributions}

NMR wrote the manuscript. LPF collected all the relevant materials including the figures and medical records. BZ performed Percutaneous Coronary

Angiography. All authors have read and approved the manuscript.

\section{Funding}

None.

\section{Availability of data and materials}

All data generated during this study are included in this published article and its supplementary information files.

\section{Ethics approval and consent to participate}

Not applicable.

\section{Consent for publication}

Written consent for publication was obtained from the patient in this case study.

\section{Competing interests}

None.

Received: 2 October 2019 Accepted: 25 November 2019

Published online: 17 December 2019

\section{References}

1. Morrad B, Yazici HU, Aydar Y, Ovali C, Nadir A. Role of gender in types and frequency of coronary artery aneurysm and ectasia. Medicine (Baltimore). 2016;95:e4395.

2. Devabhaktuni S, Mercedes A, Diep J, Ahsan C. Coronary artery Ectasia-a review of current literature. Curr Cardiol Rev. 2016;12:318-23.

3. Lin C-T, Chen C-W, Lin T-K, Lin C-L. Coronary artery ectasia. Tzu Chi Med J. 2008;20:270-4.

4. Chen $\mathrm{C}-\mathrm{H}$, Lin C-T, Lin T-K. Coronary artery ectasia presenting with recurrent inferior wall myocardial infarction. Tzu Chi Med J. 2010;22:119-22.

5. Roberts R. Genetics of coronary artery disease: an update. Methodist Debakey Cardiovasc J. 2014;10:7-12.

6. Markis JE, Joffe CD, Cohn PF, Feen DJ, Herman MV, Gorlin R. Clinical significance of coronary arterial ectasia. Am J Cardiol. 1976;37:217-22.

7. Aboeata AS, Sontineni SP, Alla VM, Esterbrooks DJ. Coronary artery ectasia: current concepts and interventions. Front Biosci (Elite Ed). 2012:4:300-10.

8. Gunduz H, Demirtas S, Vatan MB, Cakar MA, Akdemir R. Two cases of multivessel coronary artery ectasias resulting in acute inferior myocardial infarction. Korean Circ J. 2012;42:434-6.

9. Manginas A, Cokkinos DV. Coronary artery ectasias: imaging, functional assessment and clinical implications. Eur Heart J. 2006;27:1026-31.

10. Eitan A, Roguin A. Coronary artery ectasia: new insights into pathophysiology, diagnosis, and treatment. Coron Artery Dis. 2016;27:420-8.

11. Yellen $\mathrm{G}$. The voltage-gated potassium channels and their relatives. Nature. 2002:419:35-42

12. Fukai R, Saitsu H, Tsurusaki Y, Sakai Y, Haginoya K, Takahashi K, Hubshman MW, Okamoto N, Nakashima M, Tanaka F, Miyake N, Matsumoto N. De novo $\mathrm{KCNH} 1$ mutations in four patients with syndromic developmental delay, hypotonia and seizures. J Hum Genet. 2016;61:381-7.

\section{Publisher's Note}

Springer Nature remains neutral with regard to jurisdictional claims in published maps and institutional affiliations.
Ready to submit your research? Choose BMC and benefit from:
- fast, convenient online submission
- thorough peer review by experienced researchers in your field
- rapid publication on acceptance
- support for research data, including large and complex data types
- gold Open Access which fosters wider collaboration and increased citations
- maximum visibility for your research: over $100 \mathrm{M}$ website views per year
At BMC, research is always in progress.
Learn more biomedcentral.com/submissions 